\title{
A Review of the Applications of Affordance Theory in mHealth App Research
}

\author{
Moayad Alshawmar \\ Worcester Polytechnic Institute \\ malshawmar@wpi.edu
}

\begin{abstract}
Humans' relationships with objects are a crucial theoretical phenomenon in the visual perception field. Gibson contributed to the field by introducing Affordance Theory. His theory explains that humans do not interact with objects unless they perceive what the objects can afford or offer them. This position has created an ongoing debate leading IS researchers, among others, to apply the theory differently following two schools of thought. One school highlights the existence of IT artifact's affordances to users' perceptions and the IT artifact's features merging together. The other school emphasizes that the IT artifact's affordances are already embedded in its design and features. This review compares various applications of the theory made by the two schools, focusing on mHealth app studies. A framework including the various useful arguments is presented in order to guide researchers toward a better utilization and to help designers to improve IT artifact's usability and usefulness.
\end{abstract}

\section{Introduction}

Many disciplines, including Information Systems (IS), engage in theoretical debates on the core concepts of Affordance Theory [1,2]. These debates have led IS researchers to apply the theory in various ways when conducting empirical studies [2]. The ontological debates over the theory in the IS disciplines have led to the emergence of two current schools of thought; both aim to uncover the fundamental phenomena surrounding the ways in which users interact with an IT artifact to identify the artifact's affordances [3]. In other words, scholars have tried to answer the question of what can determine the value or usefulness of an IT artifact to users. The first school emphasizes that users value IT artifacts based on their perceptions of what the artifacts can afford to them $[4,5]$. This school claims that users' interactions with an IT artifact determine the affordances of the IT artifact to the particular user or users $[4,5]$. The second school of thought argues that an
IT artifact's design alone is what creates its affordances for users [6, 7]. This means that the IT-artifact's affordances are already embedded in its design, and users need only to discover them $[6,7]$.

As a result of this debate, IS researchers have applied the theory differently following one of the two schools of thought in investigating phenomena connected to the relation between IT artifacts and users. Some IS scholars have created guidelines and conducted systematic reviews to facilitate researchers' appropriate application of the theory following the views of one or the other school of thought on the theory $[2,8]$. Nevertheless, a literature review of how researchers have applied the two schools of thought while focusing on the same IT artifacts has not yet been undertaken. This task is important because it will clarify the different views on the theory and facilitate more effective future applications of it.

Thus, this literature review will focus on the way studies of mHealth apps have applied the theory following one school of thought or the other. It will focus on studies of mHealth apps that have been published in the top Information Systems journals, the "basket of 8." Unlike previous reviews which tried to uncover the affordances discovered by researchers and their impact in domains such as enterprise systems [9], social media [10], and robotic manipulation [11], the current review will investigate how researchers have applied the theory to uncover the affordances of mHealth apps, following different schools of thought. The review will focus on research on mHealth apps to learn about the variation in the uses discovered in studies investigating comparable IT-artifacts. The review will uncover the similarities and differences found among the studies. This will result in a clearer picture of how the theory has been applied and create a framework that results from combining these various applications.

This review will achieve its goals by

1. Explicating the views of the theory characterizing the two schools of thought.

2. Collecting studies of mHealth apps which have applied the theory in the eight top journals, the 
"basket of 8 ," in the IS field and used either school of thought.

3. Investigating the ways in which studies of mHealth apps have applied the theory.

4. Providing a framework on Affordance Theory that combines all of the different views.

\section{Background}

\subsection{Affordance theory - the first school of thought}

Affordance Theory was originally proposed by James Gibson [4], a psychologist and one of the most important contributors to the field of visual perception. He coined the term "affordance" to explain the relationship between animals (including humans) and the environment (surfaces, objects, places, and even other animals). Gibson [4] highlights the idea that humans interact with an object directly by perceiving what the object offers or affords to them, either for good or ill. This means humans' interactions with objects are not influenced by mediated pictures such as "retinal pictures, neural pictures, or mental pictures" [12]. Gibson [4] added the clarification that "an affordance is neither an objective property nor a subjective property; or both if you like. An affordance cuts across the dichotomy of subjective-objective and helps us to understand its inadequacy" to his definition. His clarification was not clear enough for many Ecological Psychology scholars [1]. Moreover, both humans and objects have several properties that influence and create affordances [1]. These properties have attracted scholars in Ecological Psychology to dig deeper in their efforts to define the human and environmental properties and other variables that could result in the shaping of an object's affordances for users [1]. For example, Stoffregen [13] described affordances as emergent properties of systems of humans and objects taken together. Human systems may include humans' physical and mental characteristics such as body scale, power, flexibility, talents, beliefs, and emotional states, while an object's system is its physical features, such as its shape and color [13]. Chemero [1] added to Stoffregen's [13] view of affordances (human-object system interactions) the idea that these interactions can be impacted by the whole situation that surrounds a human and object system. Therefore, an affordance initiated as a result of a human-object interaction can be changed as a result of the situation surrounding it [1].

In the IS context, Leonardi [5] pointed out that "people do not interact with an object prior to or without perceiving what the object is good for" (p. 153). Hence, the way individuals view objects (IT-artifacts) will determine the usefulness of the objects to them more than the objects' features will. Markus and Silver [14] added that affordances are not IT-artifact features but rather are enabled by IT-artifact features, and they can be shared by a group of people. This notion informs the distinction between the technology design and features (materiality) on one hand and affordances on the other. Interpreting this distinction, Strong and Volkoff [15] split the definition of affordance into three distinct processes: 1) the "potential for action," 2) "the actualization of the affordance" (action), and 3) the "immediate concrete outcome," a condition reached after these affordances are actualized. For example, one may use a system for "accessing data," "observing," "monitoring," or "investigating." Actualizing these affordances may result in reaching an immediate concrete outcome, termed "visibility" [16]. Volkoff and Strong [16] also explained that an IT-artifact comes with a bundle of affordances that are initiated within the interaction between the user and the IT-artifact. Actualizing a lower-level affordance will lead to a higher-level affordance, which results in reaching the outcome of the affordances. Volkoff and Strong [16] compared Gibson's [4] example of the biting and chewing affordances that lead to the possibility of eating an apple to the composing and then message-sending affordance using email, which will lead to the possibility of communicating. Hutchby [17] explained the influence of the social context on the interaction between a user and an IT artifact and emphasized that an IT artifact not only enables users but also constrains them from achieving the purpose for which they use the artifact. Zammuto and Griffith [18] adopted Hutchby's [17] view of affordance and constraint to uncover the influence of organizational social capacities on employees as a system's users. They concluded that a different social context may lead users to interact differently with the IT artifact [18]. The social capacities may lead to the initiation of affordances shared by a group of people. At the same time, the shared affordance may constrain other users from actualizing other affordances [18]. Thus, Zammuto and Griffith [18] defined the notion of affordance in this way: "an affordance perspective recognizes how the materiality of an object favors, shapes, or invites, and at the same time constrains, a set of specific uses."

\subsection{Affordance theory - the second school of thought}

Following this school of thought, scholars have argued that affordances are already embedded in the object and that humans need only discover them [1924]. For example, Reed [21] argued that affordances are resources of the object waiting for the right individual with the right ability to exploit them. Turvey [23] has 
defined affordances as dispositional or effectivity properties of objects which are complemented by animals' properties, suggesting, for example, that "nothing is soluble if there are no solvents." In conducting empirical studies, Heft $(1989,2001)$ defined the affordance as a relationship between an object's properties and the applicable body scale of the human, a notion in line with Warren's [25] classic study of stairclimbing affordances. Warren [25] studied how the body scale can enable some people to climb a stairway, while it disenables others from doing so.

In the context of IT, this school ascribes to IT artifacts special properties that distinguish them from other objects $[6,7]$. This distinction has led to the further step of creating a theory of affordance that works only with IT artifacts. For example, Norman [6] divided the concept of the affordance into real affordances and perceived affordances with respect to the importance of IT artifacts' features. According to Norman [6], real affordances arise when users perceive their existence in the artifact and the artifact's features deliver them. Perceived affordances are perceived by users but not delivered by an artifact's features [6]. As an example, Norman [6] used the screen, as an object that affords clicking. Since not all screens provide a feature of being clickable, he considers such a missing feature as an unpresented affordance. Hartson [26] added to Norman's [6] viewpoint two additional affordance categories: being sensory (helping the user see an affordance) and being functional (helping users relate to the overall purpose of the system). Additionally, Gaver [7] proposed a concept of affordances in which there are affordances that are perceived by users, affordances that are hidden to users, and false affordances that are unpresented, but users believe in their existence. Other authors have proposed a framework based on a mediated action perspective to distinguish between instrumental (person and object) and supplemental (maintenance, aggregation, and learning) affordances [27]. They posited that Gibson's [4] idea of the affordance is more applicable in a single-part object, while technology involves multiple parts working together [27].

\subsection{Comparing the two schools of thought}

The debate over Affordance Theory in the two fields (Ecological Psychology and IS) has been concerned primarily with the existence of an affordance of an object or IT artifact before or after humans' or users' interaction with it, and with the question of whether affordances are the features of the IT-artifact or they are results of users-the features interaction together [1, 6, 15]. Ecological Psychology scholars have tried to resolve these arguments by investigating factors such as human and object properties (abilities, effectivities, or situations) that facilitate the presence of affordances [19-24], while scholars in the IT field have focused on whether the existence of an affordance is driven by the IT artifact's features and capabilities or by the users' goals and needs $[2,6,14]$.

These differences in the schools of thought have raised three questions. The first is whether humans can define the affordances of an object or IT artifact before humans interact with the object (IT artifact). The answer is that such a definition would be impossible since there is an ongoing interaction between the object and humans. For example, the sitting affordance of a created chair was actually found after the first designer of the chair interacted with a tree and perceived that if the wood were crafted in a way that aligned it with the human body shape, it would afford sitting to people. Thus, the sitting affordance was not known until the designer of the chair interacted with the tree as an object. Further, another affordance, lying down, might appear when another human interacted with the chair. Thus, no one can determine the existence of an affordance before the human-object interaction takes place. Instead, people can only separate the affordance into material and the human perception when they interact with each other, so that an affordance might be created. In fact, Gibson [4] (p. 140) stated, "The central question for the theory of affordances is not whether they exist but whether information is available in ambient light for perceiving them."

The second question is whether affordances are properties of the object (IT artifact) or the human (user). The answer is that human properties, object properties, and other factors such as abilities, effectivities, features, or the whole situation, according to scholars of both schools, can contribute to actualizing an affordance. For example, if a person has the potential to go to the second floor of a building, a stairway can be used to afford him/her the ability to walk upwards, but given a situation in which his leg is injured (a change of ability), the elevator (with a set of features) is the only object (effectivity) that can afford him/her the ability to move upwards at that moment. Hence, it is the researcher job to find a link between human properties and object properties in order to explore affordances for a certain group of people. For example, to answer the question of why an elevator affords some people the ability to move upwards while others refuse to use it, a researcher may find that some people do not have the potential to use the elevator because they have claustrophobia (a situation); hence, the affordance to move upwards is absent for people with claustrophobia. They can also investigate the elevator's features to find the technical issues, such as the elevator's speed, that need to be improved to ensure it affords users what they need. Other factors such as policies, procedures, culture, rules, 
and regulations could impact the use and deployment of an IT artifact [28], shaping users' interactions with the IT artifact to actualize different affordances.

The third question is whether affordances can be perceived as false or hidden affordances, or whether they are always true and must be enabled by the IT artifact [6, 7]. This issue was clarified by Strong and Volkoff's [15] definition of the affordance's actualization. What cannot be actualized should not be called an affordance. Instead, it should be referred to as a potential of use. Once a user's potential has become actualizable, we can call it an affordance. Terms such as perceived, hidden, and false affordance may have similar meanings but can mislead researchers applying the theory. Thus, the affordance should be linked with what the IT artifact can afford or offer to users rather than users' imaginary uses of the IT artifact.

\subsection{Reviews in Affordance Theory}

Several reviews have been conducted to uncover the uses, effects, and implications of Affordance Theory research for the IS field. For example, Leonardi and Vaast [10] investigated the impact of enterprise social media affordances on organizations. The review also examined previous research methodologies to make recommendations that can help future researchers to strengthen their arguments [10]. Another social media review uncovered the effects of social media affordances on organizations and individuals and systematically reviewed the way the theory was being employed [29]. From a broader viewpoint, two reviews have covered how the theory had been applied in all IS research focusing on the first school's point of view [2, $8,9]$. One review concentrated on robotic research and discovered two phenomena related to users' interaction with robotic, grasping and manipulation [11]. These reviews were narrowed to explore the trends in the literature regarding the use of Affordance Theory and the impact of the discovered affordances on the specific domain. This review explores how mHealth studies have used the theory following either school of thought and compare the applications in the various studies with each other and with those found in the affordance literature. This overview clarifies the use of the theory and is of aid in gathering together the valuable arguments that have been made.

\section{Methodology}

\subsection{Literature search}

This literature review was carried out according to the guidelines in Webster and Watson [30]. The guidelines point out that major contributions are usually found in leading journals [31]. Hence, this review began by collecting and analyzing mHealth app studies published in the top IS "basket of 8" journals (European Journal of Information Systems, Information Systems Journal, Information Systems Research, Journal of AIS, Journal of Information Technology, Journal of MIS, Journal of Strategic Information Systems, and MIS Quarterly) [30]. Based on the practice in recent successful reports, the forward search was completed using the Scopus database to retrieve only articles published in the "basket of 8 " journals" [32, 33]. The search looked for the word "Affordances" anywhere in the article index in Scopus all the time until Sep, 27, 2020. The search yielded 252 studies that were screened fully by the author to include studies using Affordance Theory alone or together with another theory and focusing on mHealth apps as IT artifacts. After the review, 4 studies were included. To expand the search beyond the basket of 8 journals, the author searched for studies in other journals and conference proceedings cited by the 4 selected studies (in a backward research) by reviewing the titles and abstracts; this search resulted in 341 additional studies, none of which met the criteria. The Webster and Watson's [30] guidelines explain that the selected papers are subjective to the purpose of the literature review. Hence, when the analysis of leading journal studies was completed, the collected studies were found to be sufficient to explain the various uses of the theory and to create a framework combining all previous arguments pertaining to the theory.

\subsection{Inclusion and exclusion criteria}

\section{Inclusion criteria}

- Empirical mHealth apps articles published in the "basket of 8 journals"

- Articles applying Affordance Theory alone or together with another theory, using any methodologies.

\section{Exclusion criteria}

- Articles that used Affordance Theory but focused on an IT-artifact other than an mHealth app.

- Articles that mentioned Affordance Theory (e.g., in the background) but did not apply the theory to explain an empirical phenomenon.

Among studies in the basket of eight journals, only 4 met the criteria. 3 studies were published in the Information Systems Journal, and 1 was published in the European Journal of Information Systems. 


\subsection{Article analysis approach}

The author read and reviewed each study, focusing on (1) the goal of the study, (2) the school of thought the author(s) followed, (3) the discovered affordances of mHealth apps, (4) the way the study utilized the theory, and (5) the methodology. This information was used to compare and contrast the way the studies utilized the theory (as shown in Appendix 1).

\section{Results}

After comparing each study with the other studies and with the affordance literature, the author created concept themes. As shown in the table of concept themes (Table 2.), these themes revealed what the selected studies share and what they do not share in terms of their perspective on and application of Affordance Theory. One of the four included studies followed the first school of thought [34], and three followed the second school [35-37]. However, there were variations in the way the studies that followed the second school used the theory. All variations were categorized into themes as shown in Table 1.

Table. 1 Similar and different ways of using Affordance Theory found in the included studies.

\begin{tabular}{|l|c|l|l|l|}
\hline $\begin{array}{l}\text { Uses of Affordance } \\
\text { (AFF) Theory }\end{array}$ & \multicolumn{3}{|c|}{ Studies } \\
\hline & {$[34]$} & {$[37]$} & {$[35]$} & {$[36]$} \\
\hline $\begin{array}{l}\text { AFF emerges by } \\
\text { relationship (user and } \\
\text { IT-artifact together). }\end{array}$ & $\boldsymbol{x}$ & & & \\
\hline $\begin{array}{l}\text { AFF is limited to IT- } \\
\text { artifact capabilities. }\end{array}$ & & $\boldsymbol{x}$ & $\boldsymbol{x}$ & \\
\hline $\begin{array}{l}\text { AFF requires users' } \\
\text { perception. }\end{array}$ & $\boldsymbol{x}$ & $\boldsymbol{x}$ & $\boldsymbol{x}$ & $\boldsymbol{x}$ \\
\hline $\begin{array}{l}\text { AFF does not require } \\
\text { users' perception. }\end{array}$ & & $\boldsymbol{x}$ & & \\
\hline $\begin{array}{l}\text { AFF is one of the IT- } \\
\text { artifact's features. }\end{array}$ & & & & $\boldsymbol{x}$ \\
\hline $\begin{array}{l}\text { AFF is not one of the } \\
\text { IT-artifact's features }\end{array}$ & $\boldsymbol{x}$ & $\boldsymbol{x}$ & $\boldsymbol{x}$ & \\
\hline
\end{tabular}

\subsection{Studies and their ways of using of the theory}

4.1.1. Users' goals lead to the selection of certain mHealth app features (following the first school). James and Deane [34] adopted the relational affordance view that users' goals "shape what they come to view the features of the technology as affording them the ability to do." The authors applied goal content theory along with the Affordance Theory lens to discover how different users' goals for exercising (such as enjoyment, competence, and body appearance) can lead to using certain fitness application features. The study revealed that users who used the applications for their enjoyment and competence affordances were more likely to use features that enabled them to socialize with others [34], while those whose goal was to change their body appearance were more interested in using features that enabled them to view their exercise progress [34].

This study clarified that the IT artifact does not have to be taken as a whole to afford users what they need and want. Instead, some parts of it can provide users with what they are looking for, depending on their goals. This view is aligned with Gibson's [4] view of affordances because people's interaction with the object is driven by what the object can afford to them. Gibson [4] did not insist on viewing the object as a whole. Instead, part of it could be considered as an object itself. The authors discovered the features of the fitness app through which, with the users' interaction, some motivational affordances could be fulfilled. The authors did not limit the affordances of such apps to what they had discovered. Instead, they used goal theory, which explains a human's motivations to do exercise, and tested how these motivations could be afforded through users' interactions with the app.

4.1.2 Affordances go through a process and do not have to be perceived (following the second school). Thapa and Sein [37] stated, "affordances offer action possibilities and thus are just potentialities." The authors argued that what is more important than the discussion of the preexistence of the affordances is the actualizing of these affordances. Actualizing an affordance is what leads to the outcomes of using the IT artifact. The authors applied this view of affordance to understand the process that led doctors to perceive and actualize the affordances of a telemedicine application that was used to help doctors operate remotely in Nepal. For example, the affordances of telemedicine, such as virtual colocalizability, were reached after daily video conferences between remote doctors and local village health workers had been actualized. This resulted in the outcome of improving health care services. The authors added another affordance, "educability," which had been actualized by doctors before the doctors perceived it. The authors argued that while doctors were using the telemedicine app to operate remotely, they had also been using the app to educate interns. The authors argued that the new educability affordance was not perceived by doctors until they had actualized it on the app. The study also discovered that an affordance such as educability could lead to different affordances based on the cultural, social, and technical factors surrounding the users. For example, the educability affordance could lead doctors 
who feel that they should repay their society and educate people voluntarily to perceive a "volunteerability affordance," while the same affordance (educability) could lead other doctors who do not feel any responsibility for their society to perceive an "earnability affordance" and charge people for the education.

In this study, affordances are the capabilities of the IT artifact, and the user's potential will determine her/his selections from the capabilities to actualize what will fulfil her/his needs and wants. This view is aligned with the first school of thought, in which Gibson's view on the affordance is extended to actualization, and not just to the users' perception [15]. However, Thapa and Sein [37] contradicted Gibson's view in arguing that an affordance could be actualized without the perception of users. They made their augment referring to Volkoff and Strong's [16] unanswered question of whether there must be some level of perception (or a level of awareness) before an affordance is actualized. The authors argued that the educability affordance that they had observed was evidence that it might not be necessary for a user to perceive an affordance before it is actualized [37].

4.1.3 Affordances are already known, and users need to discover their constraints (following the second school). Mettler and Wulf [35] defined affordances as "generative mechanisms that need people to be uncovered, but which can exist regardless of a person." The authors explained how discovered affordances of wearable devices for employees, such as a workplace safety affordance, could be disabled by certain constraints such as a privacy concern for some users. They argued that wearable devices that were linked with mHealth apps could afford users who worked in a dangerous job some needed safety [35]. However, since data collected on employees would be exposed to the organization, employees with privacy concerns might not cooperate with the organization and use the device. Hence, any employees' resistance to using the devices would lead to constraining the safety affordance for them.

This study emphasized that the affordance of an IT artifact (e.g. a wearable device in this study) is already known and determined for everyone. Thus, if someone cannot actualize the affordance, it is because of the constraint for that particular user. This view is helpful for testing a discovered affordance with a number of users to learn whether it affords them the same thing. It may also mean that there will be no new affordance that can be actualized by certain user/s because the affordances are already determined, and user/s need only to uncover their constraints. This view is aligned with Gibson's [4] definition of the affordance in the sense that each individual can perceive different affordances that may or may not be aligned with other people's affordances. At the same time, it argues against Gibson's [4] definition of the affordance when it limits the affordances of IT artifacts to those that have already been discovered by others (either users or researchers). Limiting affordances to those that have already been discovered will lead to ignoring the possibility that new affordances might emerge when other users interact with an IT artifact. Thus, employees who were constrained vis-a-vis the safety affordance might have been afforded other affordances that were not uncovered. In the first school's view, an affordance cannot be constrained because the affordance is initiated through the interaction between a particular user and the IT-artifact. When a user does not have the potential to actualize what has been afforded to other users, it means that particular affordance is not an affordance for that particular user because the affordance is what the object affords or offers to that user. This does not mean that a group of people may not share the same affordance [38], but it means that what has been shared does not have to be shared by all people. Furthermore, the privacy concern (in this study) does not constrain a user from using the app. It may weaken users' potential for actualizing the app's affordance, but it does not constrain them.

\subsubsection{Affordances are the features of IT-artifacts} (following the second school). Benbunan-Fich [36] adjusted the mediated action affordance view [27] that separated affordances into instrumental (person and object) and supplemental (maintenance, aggregation, and learning) categories to study users' experiences with wearable devices. Benbunan-Fich [36] considered the instrumental interaction with wearable devices as an interaction between users and themselves since a wearable device will become a part of the users' bodies, and it is not necessary for a user to interact in physical activity to improve fitness (as is the case with exercise apps). Thus, features related to wearing (e.g., band durability, closure mechanisms, and waterresistance/moisture build-up) and interacting (e.g., tap sequence, absence of a numeric display, sleep mode activation, and random vibration) are instrumental affordances because the mediator is an extension of the self: wearing matters. On the other hand, features related to maintenance (e.g., battery life and the charging cycle) and aggregation (e.g., phone synchronization) are supplemental affordances. The study indicates that simplicity in instrumental affordances' design may result in complexity of their use because users find them hard to interact with. Also, an unbalanced relation between instrumental and supplemental affordances will impact users' experiences negatively. 
In this study, Benbunan-Fich [36] argues that the general motivation for using wearable devices is to improve one's health or lifestyle as one becomes more active in the course of everyday activities. However, the author did not consider this motivation as a wearable device's affordance or an outcome of an affordance [36]. The author, instead, considered wearing features (e.g., water-resistance/moisture build-up) and interacting features (e.g., tap sequence) along with maintenance (e.g., battery life and charging cycle) as affordances of the wearable device. The study did not ignore the fact that users may potentially interact with a wearable device to improve their health or lifestyle but also did not consider improving lifestyle to be an affordance of the wearable device as it would have been considered in the first school of thought.

Table 2. Summary of the use of Affordance Theory in the two schools.

\begin{tabular}{|c|l|}
\hline Studies & \multicolumn{1}{|c|}{ First school } \\
\hline $\begin{array}{c}\text { 1. Study } \\
\text { [34] }\end{array}$ & $\begin{array}{l}\text { Affordances are relations between users } \\
\text { and IT artifacts that are initiated through } \\
\text { users' goals and the selected features of IT } \\
\text { artifacts. }\end{array}$ \\
\hline $\begin{array}{l}\text { 2. Study } \\
\text { [37] }\end{array}$ & $\begin{array}{l}\text { Affordances are relations between users } \\
\text { and IT artifacts that are influenced by } \\
\text { external factors. Some affordances begin } \\
\text { from the user's perception and continue } \\
\text { through to actualization, while others may } \\
\text { be actualized before users perceive them. }\end{array}$ \\
\hline 3. Study & $\begin{array}{l}\text { Affordances are limited to IT artifact } \\
\text { capabilities regarding what they can afford } \\
\text { to users, and users need to discover and } \\
\text { recognize the IT-artifacts' capabilities. }\end{array}$ \\
\hline 4. Study & $\begin{array}{l}\text { Affordances are considered to be features } \\
\text { of IT artifacts, and users need to interact } \\
\text { with them. }\end{array}$ \\
\hline
\end{tabular}

\subsection{A framework that companied the literature various interpretations}

Based on the variation that can be found in conceptualizing and applying Affordance Theory, a framework of the theory was created. This framework does not disregard any previous aspects and arguments that have been raised. Instead, it considers all the aspects and arguments and organizes them in a way that reveals a certain common sense. These aspects and arguments are narrowed so that they correspond to the limitation of the affordances to the IT artifact, the perception and actualization of the affordances, the affordances' relations to the IT artifact elements, and the need for perception to actualize affordances.

These four topics are generated from the literature's definitions and the use of the theory in mHealth app research to create a framework that covers all of the arguments. The framework, as illustrated in Figure 1, holds that users, with respect to their ability, social context, regulations, and surrounding situations, interact with the IT artifact to fulfill their potential use of it. The potential shaped by the external factors drives users to actualize two types of affordance, the known and new affordance. A known affordance is one that has been discovered already through generative mechanisms (this is also defined as the general motivation in the mHealth paper which followed the second school of thought). For example, when organizations gave their employees wearable devices to improve workplace security [35] (study 3), employees were told that these devices would track their activity to improve the workplace safety. Thus, the improving workplace security affordance was known to many employees before they started using the devices. The new affordance was that an employee who used the same wearable device could have the potential to use the device to remember the places s/he visited during her/his workdays or weekdays. In this case, a memorizing affordance is a new affordance that is actualized by one user. This view is supported by Thapa and Sein's [37] paper (study 2), which found that doctors used the telemedicine application to work remotely with others (the virtual co-localizability affordance). While those doctors were using the app, other affordances such as educability and earnability appeared for some of them. However, this review does not agree with Thapa and Sein's [37] concept of actualizing affordances before perceiving them; nor does it disagree with them. Instead, this review remains silent on that point since the idea is under argument, and clear evidence remains elusive.

Actualizing affordances requires an alignment between users' characteristics and the IT artifact design to improve users' evaluation of actualized affordances. In the organization example (study 3), employees who had privacy concerns did not actualize improving their safety affordance not because the device did not enable them or because they did not have the potential but because the way the devices worked was not aligned with their beliefs (i.e., in privacy) [35]. When the affordance is actualized with an alignment between users and the IT artifact design, this will lead to a positive evaluation. In study 4 (following the second school of thought), the authors explained how the design of wearable devices (e.g., band durability or if it comes with low battery life and long charging cycles) may motivate a negative evaluation of the wearable device. The alignment may be disrupted by factors such as poor 
design of the IT artifact or users' characteristics [39]. A less complex design that aligns better with a common understanding of everyday objects will lead users to actualize IT artifact affordances in a favored way [40].

Hence, the framework explains that affordances are either known or new affordances that an IT artifact can offer to users to fulfill their potentials. Users' characteristics and the IT artifact's design alignment will determine users' evaluation when they actualize the affordances.

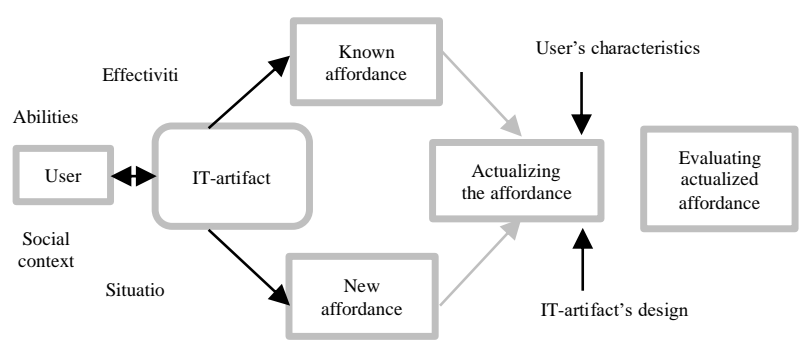

Figure 1. A framework of the affordance process from user interaction to evaluation.

\section{Discussion}

This review has aimed to explain and gather together the various applications of Affordance Theory in relation to two significant theoretical burdens. This review looked at the concepts incorporated in the two schools of thought and listed examples of studies published in the "basket of 8 journals" that applied the theory, focusing on mHealth apps. The included studies showed variation in viewing and using the theory in studies that followed the same school. Some of the studies took a direction different from that normally taken in the school they followed, while others made a slight modification. For example, Thapa and Sein [37] applied the definition of affordance that emphasizes actualization while adding a new argument that users do not need to perceive an affordance to actualize it.

The findings revealed that some of the arguments made were theoretical (e.g., affordances are embedded in the IT artifact vs. existing via a relational interaction). These conceptual differences were combined in the framework in such a way as to not ignore any arguments. For example, in the framework, the affordances embedded in the IT artifact are called "known affordances." Known affordances are those that the designer and many users know about before interacting with the IT artifact. The existence of known affordances (e.g., telemedicine apps afford virtual colocalizability [37]) does not diminish the fact that there might be other unknown affordances that could be discovered by some users (e.g., the telemedicine app affords some doctors the possibility to educate others and earn money from them). The discovered affordances are called new affordances in the framework; user/s may initiate the potential to actualize them without prior knowledge about them. Hence, affordances can be either known or new affordances. Furthermore, new affordances may become known affordances when user/s who have discovered them start revealing them to others.

Another argument was terminological. For example, the second school considered an IT artifact's features to be the affordances themselves. However, Benbunan-Fich [36] study, which considered a wearable device's features to be an affordance (applying the second school's view), did not ignore the first school's concept of affordances or that of their outcomes [16]. Instead, the authors referred to affordances' "general motivations." Affordances such as improving employees' workplace safety, mentioned by Mettler and Wulf [35] (following the second school), are similar to affordances related to improving one's health; Benbunan-Fich [35] (following the second school), called these general motivations. These affordances are also considered to be affordance outcomes in Volkoff and Strong's [16] view of the theory. The motivation and affordance outcome are all affordances of the IT artifact since they are afforded through the user-IT artifact interaction and driven by user potential. The difference between these two terms is that users do not reach these affordances (outcomes and motivations) immediately when they interact with the IT-artifact but only after actualizing some basic affordances [16].

Another argument is regarding the affordance relation to the IT artifact's features. Some consider the IT artifact' features to be the affordances. This review shows that affordance actualizations will be evaluated by the IT artifact's design and the user's characteristics aligning together. For example, a wearable device's band durability (called an affordance by Benbunan-Fich [36]), if aligned with the user's shape of hand or preference for a particular user design, will enhance the user's experience of actualizing the device affordances (e.g., tracing). Also, a wearable device that has waterresistance features (called an affordance by BenbunanFich [36]) will enhance a swimmer's experience of actualizing its affordances, while the same waterresistance features may mean nothing to people who do not swim very often. An IT artifact is designed in a way that should be aligned with users' abilities, preferences, needs, and wants [41]. Hence, this review considered the level of alignment between an IT artifact's design and users' skills, preferences, needs, and wants as a measure determining the users' evaluation when they are actualizing affordances. Once there is an alignment between IT design elements and users' characteristics, users will favor the actualization of affordances. Thus, 
IT artifacts' designs are considered to be a part of the interaction that enhances users' experience of actualizing an affordance, leading to another affordance (that could be a higher-level affordance, a general motivation, or the affordance's outcome). The framework provided in this review should help to resolve the confusion appearing in the various interpretations of the notion of affordance by including all their mentioned aspects that can shape the relationship between humans and objects in general, and IT artifacts in particular. Using the framework, researchers and developers can comprehensively take into account all the variables that are involved in the user-IT artifact relationship. This comprehensive use of the theory will lead to a clear understanding of how users utilize an IT artifact's affordances and how helpful these affordances are for achieving the overall purpose of using the IT artifact.

\section{Limitations and future research}

This review limited its search to the top IS journals, the "basket of 8," which led it to conclude with only four mHealth app studies. Such a limitation creates an opportunity for future research to expand the review by including mHealth app studies published in other respected journals. Including more mHealth app studies would reveal different patterns in applying the theory and thus increase our understanding of the theory and lead to better applications.

This review articulates Affordance Theory at an individual level and does not discuss it at an organization level. An individual's potential in using an IT artifact may not be aligned with the organization's potential in using it. Hence, future research can focus on the process organizations go through to reach their potentials in using the systems and on how employees' actualizations the systems' affordances could lead to the organizations' potentials.

\section{Conclusion}

This review contributes to the Affordance Theory literature by uncovering various theoretical arguments initiated withing two different schools of thought. The review also shows how the different schools' arguments have led to different applications of the theory in mHealth app studies. This review explained how the two schools' arguments and the way mHealth apps apply the theory are crucial and useful considerations for applying the theory. Therefore, a framework was developed to apply the theory in a way that includes all of these crucial considerations. The framework is also useful for designers seeking to improve IT artifact design.
Improving the design of an app's features that are linked with a known affordance can improve the IT artifact's usability, while discovering new affordances can help to extend the IT artifact's usefulness.

\section{References}

[1] Chemero, A., An outline of a theory of affordances. Ecological psychology, 2003. 15(2): p. 181-195.

[2] Volkoff, O. and D.M. Strong, Affordance theory and how to use it in IS research, in The Routledge Companion to Management Information Systems. 2017, Routledge. p. 232-245.

[3] Faraj, S. and B. Azad, The materiality of technology: An affordance perspective. Materiality and organizing: Social interaction in a technological world, 2012. 237: p. 258.

[4] Gibson, J.J., The theory of affordances. Hilldale, USA, 1977. 1(2).

[5] Leonardi, P.M., When flexible routines meet flexible technologies: Affordance, constraint, and the imbrication of human and material agencies. MIS quarterly, 2011. 35(1): p. 147-167.

[6] Norman, D.A., Affordance, conventions, and design. interactions, 1999. 6(3): p. 38-43.

[7] Gaver, W.W. Technology affordances. in Proceedings of the SIGCHI conference on Human factors in computing systems. 1991. Acm.

[8] Fromm, J., M. Mirbabaie, and S. Stieglitz, A SYSTEMATIC REVIEW OF EMPIRICAL AFFORDANCE STUDIES: RECOMMENDATIONS FOR AFFORDANCE RE-SEARCH IN INFORMATION SYSTEMS. 2020.

[9] Pozzi, G., F. Pigni, and C. Vitari. Affordance theory in the IS discipline: A review and synthesis of the literature. 2014.

[10] Leonardi, P.M. and E. Vaast, Social media and their affordances for organizing: A review and agenda for research. Academy of Management Annals, 2017. 11(1): p. $150-188$.

[11] Yamanobe, N., et al., A brief review of affordance in robotic manipulation research. Advanced Robotics, 2017. 31(19-20): p. 1086-1101.

[12] Gibson, J., The ecological approach to visual perception. Boston, MA, US. 1979, Houghton, Mifflin and Company.

[13] Stoffregen, T.A., Affordances as properties of the animal-environment system. Ecological psychology, 2003. 15(2): p. 115-134.

[14] Markus, M.L. and M.S. Silver, A foundation for the study of IT effects: A new look at DeSanctis and Poole's concepts of structural features and spirit. Journal of the Association for Information systems, 2008. 9(10): p. 5.

[15] Strong, D.M., et al., A theory of organization-EHR affordance actualization. Journal of the Association for Information Systems, 2014. 15(2): p. 2.

[16] Volkoff, O. and D.M. Strong, Affordance theory and how to use it in IS research. The Routledge companion to management information systems. New York: Routledge, 2018. 
[17] Hutchby, I., Technologies, texts and affordances. Sociology, 2001. 35(2): p. 441-456.

[18] Zammuto, R.F., et al., Information technology and the changing fabric of organization. Organization science, 2007. 18(5): p. 749-762.

[19] Heft, H., Affordances and the body: An intentional analysis of Gibson's ecological approach to visual perception. Journal for the theory of social behaviour, 1989. 19(1): p. 1-30.

[20] Michaels, C.F., Information, perception, and action: What should ecological psychologists learn from Milner and Goodale (1995)? Ecological Psychology, 2000. 12(3): p. 241-258.

[21] Reed, E.S., Encountering the world: Toward an ecological psychology. 1996: Oxford University Press.

[22] Stoffregen, T.A., Affordances and events. Ecological psychology, 2000. 12(1): p. 1-28.

[23] Turvey, M.T., Affordances and prospective control: An outline of the ontology. Ecological psychology, 1992. 4(3): p. 173-187.

[24] Heft, H., Ecological psychology in context: James Gibson, Roger Barker, and the legacy of William James's radical empiricism. 2001: Psychology Press.

[25] Warren, W.H., Perceiving affordances: Visual guidance of stair climbing. Journal of experimental psychology: Human perception and performance, 1984. 10(5): p. 683.

[26] Hartson, R., Cognitive, physical, sensory, and functional affordances in interaction design. Behaviour \& Information Technology, 2003. 22(5): p. 315-338.

[27] Kaptelinin, V. and B. Nardi. Affordances in HCI: toward a mediated action perspective. in Proceedings of the SIGCHI Conference on Human Factors in Computing Systems. 2012. ACM.

[28] Sittig, D.F. and H. Singh, A New Socio-technical Model for Studying Health Information Technology in Complex Adaptive Healthcare Systems. Quality \& safety in health care, 2010. 19(Suppl 3): p. i68.

[29] Hafezieh, N. and F. Eshraghian. Affordance theory in social media research: Systematic review and synthesis of the literature. in 25th European Conference on Information Systems (ECIS 2017). 2017.

[30] Webster, J. and R.T. Watson, Analyzing the past to prepare for the future: Writing a literature review. MIS quarterly, 2002: p. xiii-xxiii.
[31] Lowry, P.B., D. Romans, and A.M. Curtis, Global journal prestige and supporting disciplines: A scientometric study of information systems journals. Global journal prestige and supporting disciplines: A scientometric study of information systems journals. Journal of the Association for Information Systems (JAIS), 2004. 5(2): p. 29-80.

[32] Zahedi, M., M. Shahin, and M.A. Babar, A systematic review of knowledge sharing challenges and practices in global software development. International Journal of Information Management, 2016. 36(6): p. 995-1019.

[33] Shahin, M., M.A. Babar, and L. Zhu, Continuous integration, delivery and deployment: a systematic review on approaches, tools, challenges and practices. IEEE Access, 2017. 5: p. 3909-3943.

[34] James, T.L., J.K. Deane, and L. Wallace, An application of goal content theory to examine how desired exercise outcomes impact fitness technology feature set selection. Information Systems Journal.

[35] Mettler, T. and J. Wulf, Physiolytics at the workplace: Affordances and constraints of wearables use from an employee's perspective. Information Systems Journal, 2019. 29(1): p. 245-273.

[36] Benbunan-Fich, R., An affordance lens for wearable information systems. European Journal of Information Systems, 2018: p. 1-16.

[37] Thapa, D. and M.K. Sein, Trajectory of A ffordances: Insights from a case of telemedicine in Nepal. Information Systems Journal, 2018. 28(5): p. 796-817.

[38] Leonardi, P.M., When does technology use enable network change in organizations? A comparative study of feature use and shared affordances. MIS quarterly, 2013: p. 749-775.

[39] Vaghefi, I. and B. Tulu, The Continued Use of Mobile Health Apps: Insights From a Longitudinal Study. JMIR mHealth and uHealth, 2019. 7(8): p. e12983.

[40] Norman, D.A., The psychology of everyday things. 1988: Basic books.

[41] Liu, D., R. Santhanam, and J. Webster, Toward Meaningful Engagement: A Framework for Design and Research of Gamified Information Systems. MIS quarterly, 2017. 41(4).

\begin{tabular}{|l|l|l|l|}
\hline Study school & Purpose of the study & Affordances (discovered or used) & Way of the use \\
\hline [34] First school & $\begin{array}{l}\text { Uncover the impact of users' goals for } \\
\text { exercising such as enjoyment on using } \\
\text { certain fitness application features. }\end{array}$ & $\begin{array}{l}\text { Intrinsic: 1. enjoyment/interest 2. competence } \\
\text { Extrinsic:1. appearance 2. fitness }\end{array}$ & $\begin{array}{l}\text { Different purpose of doing exercise } \\
\text { (enjoyment) will lead users to use mHealth } \\
\text { app features differently. }\end{array}$ \\
\hline $\begin{array}{l}\text { [37] Second } \\
\text { school }\end{array}$ & $\begin{array}{l}\text { Study the process to perceive and } \\
\text { actualize affordances of telemedicine. }\end{array}$ & $\begin{array}{l}\text { 1. virtual co-localisability 2. volunteerability } \\
\text { 3. educability 4. earnability }\end{array}$ & $\begin{array}{l}\text { While using the app, users may actualize } \\
\text { new affordances without their perception. }\end{array}$ \\
\hline $\begin{array}{l}\text { 35] Second } \\
\text { school }\end{array}$ & $\begin{array}{l}\text { Discover the perceptions of employees } \\
\text { on the organization's wearable devices. }\end{array}$ & $\begin{array}{l}\text { 1.improve workplace security. 2. better adapt to the work } \\
\text { Environment. 3. improve awareness and cognition 4. signal } \\
\text { adherence to group norms and values }\end{array}$ & $\begin{array}{l}\text { Used already discovered affordances to } \\
\text { uncover what could constrain users from } \\
\text { actualizing these affordances. }\end{array}$ \\
\hline $\begin{array}{l}\text { [36] Second } \\
\text { school }\end{array}$ & $\begin{array}{l}\text { Learn how users incorporate them into } \\
\text { their lives and whether they derive the } \\
\text { benefits they expect. }\end{array}$ & $\begin{array}{l}\text { Instrumental affordances: 1. band durability 2. closure mechanism } \\
\text { 3. water-resistance/moisture build-up 4. tap sequenc 5. no numeric } \\
\text { display 6. sleep mode activation 7. random vibration } \\
\text { Supplemental affordances: } 1 \text {. battery life and charging cycle 2. } \\
\text { phone synchronization }\end{array}$ & $\begin{array}{l}\text { Users with the motivation to use wearable } \\
\text { devices interact with the devices' } \\
\text { affordances (features). }\end{array}$ \\
\hline
\end{tabular}

